\title{
Enhanced Engagement Nurtured by Determination, Efficacy, and Exchange Dimensions (EENDEED): A Nine-Item Instrument for Measuring Traditional Workplace and Remote Employee Engagement
}

\author{
Franklin M. Lartey ${ }^{1} \&$ Phillip M. Randall ${ }^{2}$ \\ ${ }^{1}$ Lartey Research and Management, Marietta, GA, United States of America \\ ${ }^{2}$ School of Business, Technology, and Health Care Administration, Capella University, Minneapolis, USA \\ Correspondence: Franklin M. Lartey, Lartey Research \& Management, 320 Old Orchard Ct., Marietta GA 30068, \\ USA.
}

Received: December 9, 2021

Accepted: January 10, 2022

Online Published: January 18, 2022

doi:10.5539/ibr.v15n2p1

URL: https://doi.org/10.5539/ibr.v15n2p1

\begin{abstract}
With the ongoing pandemic and technological evolutions, remote work has become the new normal. However, existing employee engagement instruments do not take the remote aspect of work into account. This paper proposes a nine-item instrument for assessing employee engagement in general, and remote worker engagement specifically. The instrument was named EENDEED, for enhanced engagement nurtured by determination, efficacy, and exchange dimensions. It was grounded on three theories: (1) self-determination; (2) self-efficacy; and (3) social exchange. After generating the proposed scale grounded on the literature and theory, data were collected from 626 participants in the United States through an online survey. The dataset was split in two random samples of 405 and 195 cases respectively, after eliminating 26 cases with missing values. An exploratory factor analysis (EFA) on the larger sample helped discover its two-factor structure, namely PERFORMANCE and SELF-RELIANCE. A confirmatory factor analysis (CFA) was performed on the second sample, which confirmed the two-factor structure of EENDEED. A final study assessed the reliability and validity of EENDEED. Data were collected through an online survey of 162 employees in the U.S. A CFA was conducted, validating the two-factor structure of the instrument. Construct reliability of the factors and reliability of the scale were ascertained. Face validity, content validity, construct validity, and criterion validity were confirmed. This study fills the gap in current engagement measurements by including the remote worker dimension. Organizations will be better able to identify and address challenges faced by traditional workplace employees and remote workers.
\end{abstract}

Keywords: employee engagement, engagement scale, engagement instrument, remote worker, remote employee, worker engagement, self-determination, self-efficacy, social exchange

\section{Introduction}

Reportedly, the trend of working remotely began in Germany in 1967 as "flextime" (Allen et al., 2010). Over time, flextime became known as telework. In 1973, flextime was adopted by Hewlett-Packard in the United States to allow employees more flexibility with work schedules (Hewlett-Packard, 2017). Telework continued to grow, increasing from 23.5 million Americans working remotely at least once per month in 2003 to 33.7 million in 2008 (WorldatWork, 2009). According to a recent Gallup Report (Brenan, 2020), 57\% of U.S. workers work from home; therefore, work and home blended amid the 2019 Covid-19 pandemic. Three in five U.S. workers who have been doing their jobs from home during the pandemic would prefer to continue with remote work as much as possible once public health restrictions are lifted (Brenan, 2020).

As employees' work moves from the traditional (non-remote) office to remote locations, such as homes, researchers must better understand remote worker behaviors to forecast expectations and impacts on organizational effectiveness (Johnston et al., 2013). Increasingly, companies should re-evaluate policies and procedures that inform and govern organizational practices regarding communications, relationships, inclusiveness, equity, and promotions.

Some jobs, such as retail cashiers or garbage disposal crews, may not have an option to telecommute or work remotely. Yet technology has made remote work a viable option for many jobs. In addition, it is, at times, a 
preferred way of doing business. This assertion is corroborated by Marcia G. Rhodes, the spokeswoman for WorldatWork, an international human resources company, who explained that teleworking is best suited to jobs that are information-based, predictable, portable, or that demand a high degree of privacy and concentration (WorldatWork, 2009). Moreover, human relationships are fundamental in the work environment. Even when employees work remotely, relationships are critical to successfully achieve organizational results. Thus, the engagement of remote workers is investigated in this study, along with that of traditional workplace employees.

Current research suggests that employee engagement among workers, in general, is on the rise (Hart, 2020). Still, other research reveals that remote workers, particularly, have an increased level of disengagement, lack of self-efficacy, and lack of trust due to separation and isolation from organizational leadership (Budworth \& Latham, 2009; Isaac et al., 2001; Lombardo, 2011; Yakovleva et al., 2010). Arguably, the geographical distance may produce disengaged remote workers who lack self-efficacy and feel frustrated with their leaders (Barsness et al., 2005).

The general problem for this research is based on a recent explosion in the number of remote workers due to the Covid-19 pandemic, as well as the paucity of research on remote worker engagement. Current employee engagement instruments are adequate for measuring engagement in a traditional workplace setting, in which employees work in office buildings and have direct contact with leadership and colleagues. However, the literature lacked an instrument to address remote employee engagement. The engagement of remote employees is currently viewed from the same lens as that of traditional employees, even though differences in their working conditions likely contribute to their level of engagement or disengagement.

The purpose of this study is threefold: (1) describe the development of an enhanced instrument for measuring the engagement of both remote workers and traditional workplace employees; (2) identify and confirm the instrument's factor structure; and (3) assess the validity and reliability of the instrument. The steps used to achieve this goal are presented in Figure 1, which also depicts the flow of this article.

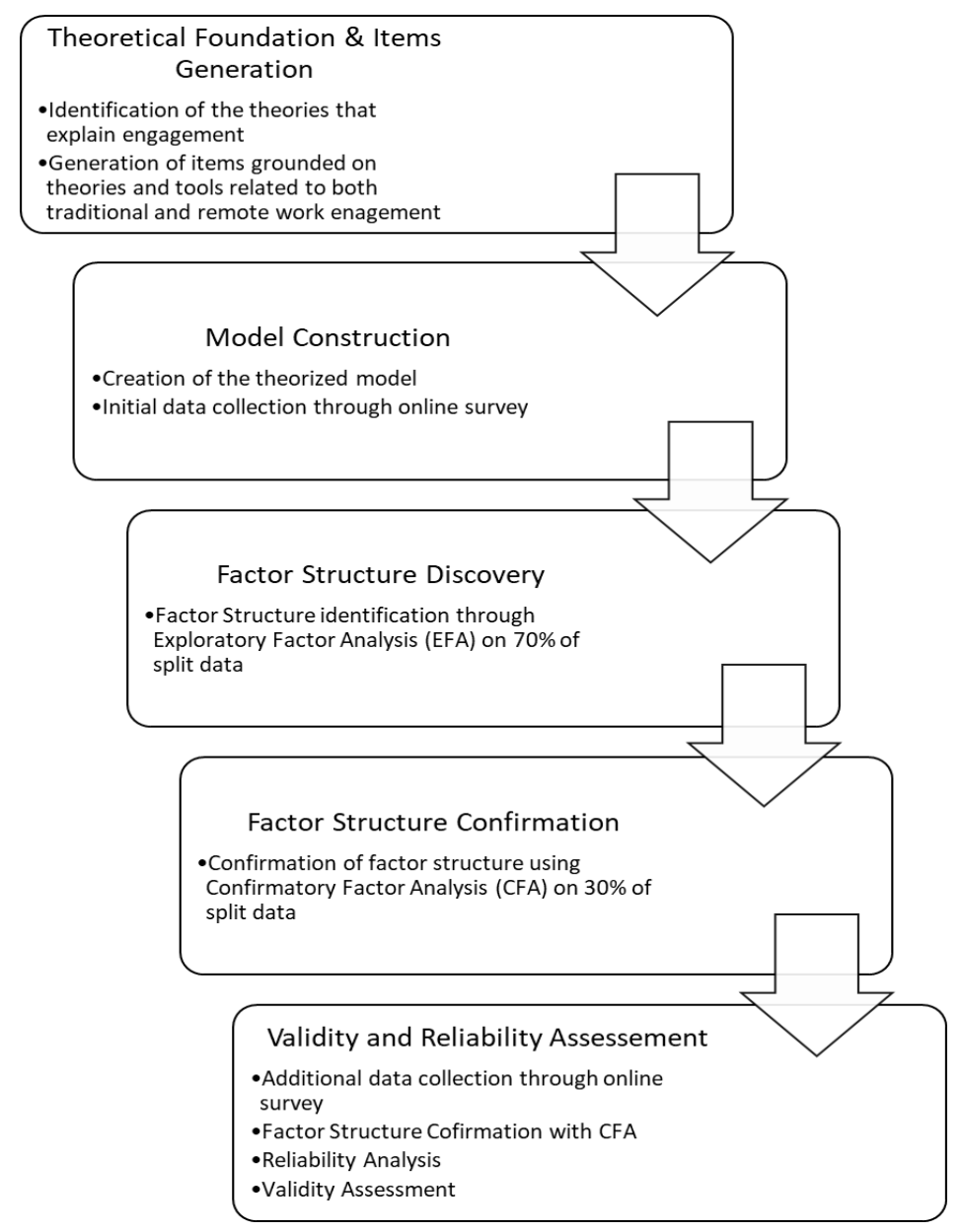

Figure 1. Steps used for the development and validation of EENDEED 


\section{Study 1: Grounded Discovery of Scale Items}

This research was sub-divided into three studies during the creation of an instrument to measure employee engagement and remote work. This type of structure was used by several researchers' creation of scales. For example, in the creation of SERVQUAL, a scale for measuring consumer perception of service quality, Parasuraman et al. (1988) proceeded with the generation of scale items, the first and second stages of data collection and purification, and scale assessment and validation. Similarly, Malone et al. (2012) conducted three studies with scale development, scale analyses, and scale validation when creating the general belongingness scale (GBS). In this article, the first study focuses on the discovery of scale items. It is grounded on various theories. To achieve its goal, this first study was qualitative in nature and included the theoretical foundations of work and remote work, presentation of remote work and engagement, analysis of theories (self-determination, self-efficacy, and social exchange), and generation of initial scale items.

\subsection{Employee Engagement}

Regarding organizational performance and business success, time and experience have confirmed that employee engagement is the differentiating factor in producing a desired or intended result (Bakker \& Schaufeli, 2008). A valuable gauge of an organization's effectiveness is its ability to sow the seeds of engagement of human capital. Effective organizations require employees with high levels of involvement and commitment to their work and the associated organization's success (Bakker et al., 2011).

Schaufeli and Bakker (2004) described employee engagement as the willingness to invest all of oneself into work while being strongly married to it in a way time passes quickly and disconnection from the role is a major difficulty. This description of employee engagement is arguably the desired state of an organization's well-being and livelihood (Schaufeli, 2014). In organizational research, employee engagement is an attractive and powerful construct associated with other key constructs in successful workplace, including job satisfaction (Hakanen et al., 2006), positive attitude toward a job (Harter et al., 2002; Schaufeli et al., 2006), organizational commitment (Saks, 2006), and organization citizen behavior (Bakker \& Bal, 2010; Rich et al., 2017).

Significant research has been done regarding employee engagement; however, little has been done to address the engagement of remote workers. The practice of remote work employees is enabled by increases to technological advances within an organization (Ter Hoeven \& Van Zoonen, 2015). The rapid development of information and communication technologies (ICTs) has made it possible for workers to access their work from any place and at any time via laptops, tablets, and smartphones (Maitland \& Thomson, 2014).

\subsection{Remote Work}

The subject of remote worker engagement is forced into focus in the wake of an added set of workplace circumstances brought on by the Covid-19 pandemic. Clearly, the engagement of remote workers in the success of an organization is of utmost concern due to physical distance. This is a new workplace challenge for human resource professionals to ponder. Considering the growing use of technology, as well as the consequent increase in the need to be flexible around where work is conducted, organizations must be attentive to the benefits and pitfalls of remote working practices and remote worker engagement.

Evolutions in communication technologies, as well as constraints from Covid-19, have contributed to the magnification of an emerging organizational structure termed the "virtual organization." In this structure, individuals work toward the achievement of a common goal; however, they do not have centralized buildings, physical plants, or other characteristics of a traditional organization (Hartman \& Guss, 1996). The virtual organization challenges current management thinking, organizational designs, and functionality. Increasingly, virtual organizations are becoming an ever-present organizational design accompanied by the advent of remote workers and the need for their engagement and productivity. This organizational structure, coupled with ICT advancements, places unique strains on communication and management processes, which must be reimagined for organizations to effectively harvest the new structure's potential benefits (Tate et al., 2019).

"Telecommuting" was an early term used to refer to remote working arrangements (Nilles, 1975), specifically individuals who used technology to work from home and communicate with their workplace. According to Madsen (2001), telecommuting and telework have been extensively used in the U.S. to refer to all types of work performed outside a head office (but still linked to the office). Remote worker describes "work being completed anywhere and at any time regardless of location and to the widening use of technology to aid flexible working practices" (Grant et al., 2013, p. 3). According to this definition, remote work can be conducted from home, company sites, hotels, airports, and other remote locations. The current study will employ "remote worker" as a general term to include any employee who spends time away from the traditional office and uses technology to 
access work (Grant et al., 2013).

In a study seeking the relationship between the use of computer-mediated communication (CMC) and engagement, Tate et al. (2019) used the CMC framework created by Spitzberg (2006). This framework included the following 15 subscales (Bubas, 2006): Motivation, Knowledge, Coordination, Expressiveness, Attentiveness, Composure, Efficacy, General Usage, CMC Interactivity, Task Orientation, Appropriateness, Effectiveness, Satisfaction, Co-orientation, and Productivity/Efficiency.

Tate et al. (2019) used five of these subscales in their study: (1) expressiveness; (2) attentiveness; (3) efficacy; (4) knowledge; and (5) motivation. This selection was based on existing literature on possible relationships with engagement. Using a multiple regression model, the authors identified the main drivers of engagement as attentiveness, expressiveness, and motivation. They concluded that efficacy and knowledge did not contribute to employee engagement.

Overall, the current study aims at using an amalgamation of self-determination theory, self-efficacy theory (SEFT), and social-exchange theory to inform the best course of action to enable remote and traditional worker engagement and productivity. This effort will identify and understand the antecedents to workers' self-determination, self-efficacy, and social exchange, as well as the associated behavioral and organizational consequences.

\subsection{Conceptualization of Engagement and Theoretical Framework}

The topic of engagement has continued to gain interest. It has been studied using customers (Bowden, 2009; Chandni \& Rahman, 2020; White et al., 2010), students (Carmona-Halty et al., 2019; Macey \& Schneider, 2008), and employees (Anitha, 2014; Men et al., 2020; Tate et al., 2019). Common to all the studies is the notion that engagement is a human character in the execution of a task, job, or work. In this article, the construct of engagement is studied in application to all employees, including remote workers.

Engagement is characterized by a positive attitude and will to involve oneself in a task while staying deeply connected with the work. These mental states were characterized by Schaeufeli and Bakker (2004) as vigor, dedication, and absorption.

Studies on employee engagement have demonstrated and confirmed the existence of a statistically significant relationship between the construct of engagement and employee performance (e.g., Anitha, 2014; Gull et al., 2020), company profitability (e.g., Kazimoto, 2016), customer satisfaction (e.g., Salanova et al., 2005), employee belongingness and retention (e.g., Randall et al., 2020; Shuck et al., 2014), and factors like productivity, job satisfaction, safety, and organizational commitment. To that effect, employee engagement is an important construct of success for any organization.

This study aligns with Lartey (2021) in defining engagement as:

a two-way relationship between an organization and a worker in which the organization provides the worker with the environment and conditions to be successful through good leadership and management, and the worker provides the organization with a positive and self-motivated performance leading to the achievement of the organizational mission, vision, purpose, and goals. (p. 137)

Arguably, this definition is applicable for both traditional and remote workers. On one hand, this view suggests the existence of mutual collaboration for shared benefits as supported by the social exchange theory (SET). On the other hand, it suggests the display of self-motivation from the employee as supported by the self-determination theory (SDET), as well as a display of unmanaged work performance as supported by the self-efficacy theory (SEFT).

The conceptualization of engagement can be viewed on Figure 2.

To understand how workplace conditions were elevated, magnified, and accelerated by the Covid-19 pandemic, three theoretical sources were employed in this study of remote worker engagement in particular (i.e., self-determination, self-efficacy, and social exchange theories). These psychological theories were chosen because of their reported predictive and explanatory powers to effect personal and social changes. 


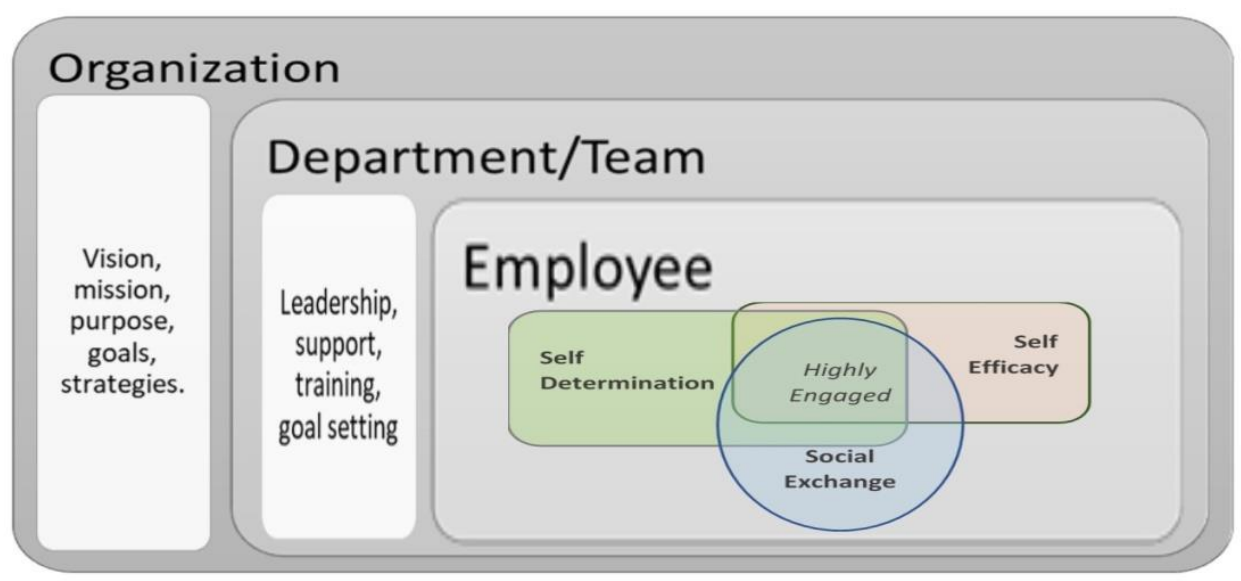

Figure 2. Diagram depicting the conceptual view of employee engagement as it relates to the organization through the influence of leadership. As presented, highly engaged employees are characterized by a combined sense of self-determination, self-efficacy, and social exchange. In addition, company employees in structured teams can work both in the conventional workplace and/or remotely.

\subsection{SDET: Self-Determination Theory}

Intrinsic motivation (as opposed to extrinsic motivation) suggests interest, enjoyment, satisfaction, and gratification in a task (Ryan \& Deci, 2000). Self-determination is an intrinsic motivation generated by internal inducements (Deci \& Ryan, 1985; Garrin, 2014; Sweet et al., 2014). It refers to a person's ability to make choices and drive actions toward the achievement of a desired outcome. Self-determined people feel a sense of autonomy and control over their choices, which leads to a greater state of motivation and engagement as suggested by the self-determination theory.

The self-determination theory is an approach to explain human motivation based on the assumption that people naturally and actively seek growth and self-organization (Deci \& Ryan, 1985; Garrin, 2014; Legault, 2017). It suggests that people are self-determined when three basic psychological needs are fulfilled: (1) competence (ability to feel effective when doing something); (2) autonomy (need for freedom and self-direction); and (3) relatedness (need to feel connected to others). The self-determination theory is, in fact, a metatheory of six sub-theories, each centered around the three main constructs of self-determination (competence, autonomy, and relatedness).

The first sub-theory, the cognitive evaluation theory, seeks to identify factors that explain variability in intrinsic motivation as explained by Ryan and Deci (2000). The second sub-theory is the organismic integration theory, which focuses on extrinsic motivation and internalization. The third sub-theory, causality orientation theory, looks at personality disposition to explain if individuals are autonomous, controlled, or neutral (Legault, 2017). The fourth sub-theory is the basic psychological need theory. It looks at the role of psychological needs in individuals' well-being. The fifth sub-theory, goal content theory, focuses on the influence of individual health and well-being through both intrinsic and extrinsic motivations. Finally, the sixth sub-theory, relationship motivation theory, looks at the need to develop and maintain collaborative relationships. These six sub-theories are not viewed separately in this study. Instead, they are covered under the umbrella of the self-determination metatheory and its three main constructs (competence, autonomy, and relatedness).

\subsection{SEFT: Self-Efficacy Theory}

The SEFT maintains that people are likely to engage in activities to the extent that they perceive themselves to be capable and/or competent. It is defined as:

people's judgments of their capabilities to organize and execute courses of action required to attain designated types of performances. It is concerned not with the skills one has but with judgments of what one can do with whatever skills one possesses. (Bandura, 1986, p. 391)

Bandura (1994) later defined self-efficacy as "people's beliefs about their capabilities to produce designated levels of performance that exercise influence over events that affect their lives" (p. 2). In other words, self-efficacy is one's belief in their ability to influence events that affect one's life, as well as having control over the way these events are experienced. 
Bandura's (1994) SEFT follows the principle that people are likely to engage in activities when they feel that they are competent in performing those activities. There are reportedly four sources of self-efficacy:

1. Performance Accomplishments: These accomplishments are achieved through mastery experiences as successes build a robust belief in one's personal efficacy.

2. Vicarious Experience: These experiences are provided by social models. Seeing people like oneself succeed by sustained effort raises an observer's belief that they possess the capabilities to master comparable activities and success.

3. Social Persuasion: When employees are persuaded verbally, they can master given activities, put forth more effort, and sustain the task. This is unattainable if they harbor self-doubt and dwell on personal deficiencies when problems arise.

4. Physiological and Emotional States: These states can reduce stress reactions and alter negative emotional proclivities and/or misinterpretations of their physical states.

Self-efficacy is a direct predictor of the intention of one's behavior. In defining the concept of self-efficacy, the most important point to be considered is that self-efficacy scales must be tailored to specific domains of functioning. Thus, self-efficacy instruments should be named for the behavioral domain they represent. Self-efficacy is related to the specific behaviors and contexts in which it occurs (Bandura, 1994).

To address this concern in the literature, the primary construct and associated variable to be measured will be presented within the context of the general self-efficacy (GSE), a derivative of self-efficacy. According to Judge et al. (1998), GSE is an "individual's perception of their ability to perform across a variety of different situations" (p. 170). Scherbaum et al. (2006) stated that self-efficacy:

has been conceptualized as a relatively stable generalized belief that an individual can marshal the resources needed to deal with the challenges that he or she experiences. That is, GSE is a trait-like belief in one's competence. (p. 1049)

According to Bandura (2006), the "one measurement fits all" approach is of limited explanatory and predictive value because most of the items in an all-purpose test may have little or no relevance to the area of function to be studied. Thus, it is advisable to consider the use of a scale that provides for and addresses GSE, allowing for general function application. This study advanced the use of a six-item short form of the GSE scale developed by Romppel et al. (2013).

\subsection{SET: Social Exchange Theory}

The SET is a theoretical model that contributes to the understanding of workplace behavior. Its two diverse paths or forms of exchange are social and economic (Blau, 1964; Gouldner, 1960; Homans, 1958; Slack et al., 2015). Blau (1964) defined social exchange as "the voluntary actions of individuals that are motivated by the returns they are expected to bring and typically do in fact bring from others" (pp. 91-92). Tate (2015, p. 44) highlighted that "an important concept of SET is that a person favorably considers others with the expectation of something in return." Blau (1964) revealed that the definite nature is not specified in advance or at the time of the favor and the discretion is left to the one who makes it. This means that the social exchange path is more general; the terms of the exchange are not stated. Therefore, based on a general obligation to reciprocate, the social exchange is deeply entrenched in constant exchange and undetermined exchange of favors (Aryee et al., 2002; Kim \& Kuo, 2015).

In contrast, the economic exchange is a binding agreement that recognizes the negotiated exchange tied to financial gain between an employer and employee in the workplace setting (Deckop et al., 2003). Many scholars found the economic exchange to exemplify quid pro quo between employee and employer (Aryee et al., 2002; Blau, 1964), which explains why employees may engage in extra-role activities (Ryan, 2001). Despite the different ways scholars used SET, they agreed that the exchange affiliation is both social and economic, characterizing "a two-sided, mutually contingent, and mutually rewarding process involving 'transactions' or simply 'exchange" (Emerson, 1976, p. 336).

The SET's evidence-based history dates back over 60 years. The SET began by bridging disciplines like social psychology (Blau, 1964; Gouldner, 1960; Homans, 1958), sociology (Blau, 1964), human resources (Shuck et al., 2014), management (Rosen et al., 2011), organizational behavior (Michel \& Tews, 2016), and psychology (Meyer, 2013). Scholars deployed several approaches regarding psychology for instrumental behaviors (Homans, 1958), technical-economic analysis (Blau, 1964), norm of reciprocity (Gouldner, 1960), and psychological concepts (Thibaut \& Kelley, 1959). Collectively, these works established the foundation for exchange relations (Emerson, 1976). 


\section{Scale Items Generation}

\subsection{Self-Determination-Based Items}

In a quantitative peer-reviewed article analyzing the indicators of computer-mediated communication that affect remote employee engagement, Lartey and Randall (2021a) used an online questionnaire to survey 133 remote knowledge workers in the U.S. Their survey questionnaire included the Utrecht Work Engagement Scale (UWES-9) to measure employee engagement and the CMC competency scale to measure competency in computer-mediated communication and regress its items to the engagement scores. A multiple regression model was created, showing the existence of a statistically significant relationship between the independent variables (IVs) (empathy, expressiveness, and motivation) and the dependent variable (DV) (remote employee engagement). The results confirmed that empathy, expressiveness, and motivation contributed significantly to remote employee engagement. These three items, which were represented by their respective assertions in the $\mathrm{CMC}$ instrument, were selected for inclusion in the EENDEED scale as follows.

- Empathy: I show concern for and interest in the person I am conversing with, in my communication and messages.

- Expressiveness: I use a lot of expressive symbols in my communication and messages (e.g., :) or $\odot$ ) for "smile").

- Motivation: I look forward to sitting down at my computer to write to others or do my daily work.

Regarding the remote dimension and employee engagement, research by Lartey and Randall (2021a) focused on the self-determination theory. Indeed, empathy, expressiveness, and motivation are intrinsic to the employee and demonstrate natural tendencies for healthy behaviors. In addition, these items align with the basic needs for competency, autonomy, and relatedness as suggested by Ryan and Deci (2000) in their framework defining self-determination. Empathy can be tied to relatedness, expressiveness can signal autonomy, and motivation can signal competence. These three items were, thus, selected for inclusion in the current study as part of the resulting EENDEED instrument.

\subsection{Self-Efficacy-Based Items}

In a self-efficacy-based study analyzing the items of the balanced measure of psychological needs (BMPN) that affect employee engagement, Lartey and Randall (2021b) studied the BMPN indicators that affect employee engagement. More specifically, the authors explored whether confidence, interest, authenticity, and loneliness were predictors of engagement. After gathering data from 151 participants, an initial data analysis reduced the usable sample size to 134 cases. A multiple regression model was created; the results suggested that confidence, interest, and authenticity were statistically significant in measuring employee engagement. However, loneliness was not significant. The analysis confirmed that a model created with confidence, interest, and authenticity could explain $56.5 \%$ of the variance in employee engagement. These findings contributed to research in employee engagement, having implications for both practitioners and academia. Suggestions for further research included the need to identify other contributors to employee engagement. To that effect, the contributing factors of engagement were selected for inclusion in the current study. As such, the following items were added to the new instrument:

- Confidence: I successfully complete difficult tasks and projects.

- Interest: I am really doing what interests me.

- Authenticity: My choices express my "true self."

As presented, the items identified align with the principles of the SEFT. Indeed, Bandura (1994) defined self-efficacy as the capacity for someone to believe in their ability to influence events that affect their life. The three assertions (confidence, interest, and authenticity) depict a person's belief and confidence in their abilities and choices. They were, thus, selected for integration in EENDEED from a self-efficacy perspective.

\subsection{Social-Exchange-Based Items}

In a quantitative non-experimental correlational study, Lartey (2021) surveyed 120 participants in small- and medium-sized companies in the U.S. The goal of the study was to establish the relationship between the IVs (career planning, employee autonomy, manager recognition) and DV (employee engagement) as defined by the UWES-9 scale. A standard multiple regression statistical model was created and analyzed. Findings from the study confirmed that career planning, autonomy, and recognition had a statistically significant relationship with employee engagement. These findings confirmed the premises of the SET, which states that employees would engage in a behavior if the benefits outweigh the cost. It also aligned with the definition of engagement by 
Lartey (2021), which looks at engagement as a two-way relationship in which the employee gets leadership, support, and reward from the organization and contributes, in return, to the success of the organization.

Career planning is a vision of the employee's future as agreed upon by the employee and manager. Autonomy is a sign of trust from the organization to the employee. Manager recognition is a signal to the employee that they are on the right path toward the achievement of their established career goal. The three items presented by Lartey (2021) were selected for inclusion in the proposed instrument. These items were as follows:

- Career Planning: "I had a career-planning discussion with my manager."

- Autonomy: "I have control over the quality of my work."

- Recognition: "I am satisfied with the recognition I receive from my manager."

The proposed scale, as represented in Figure 3, depicts engagement from the lens of the three identified theories as suggested by EENDEED. This suggests a nine-item instrument in which each construct will be represented by an assertion or question to be answered by the respondent.

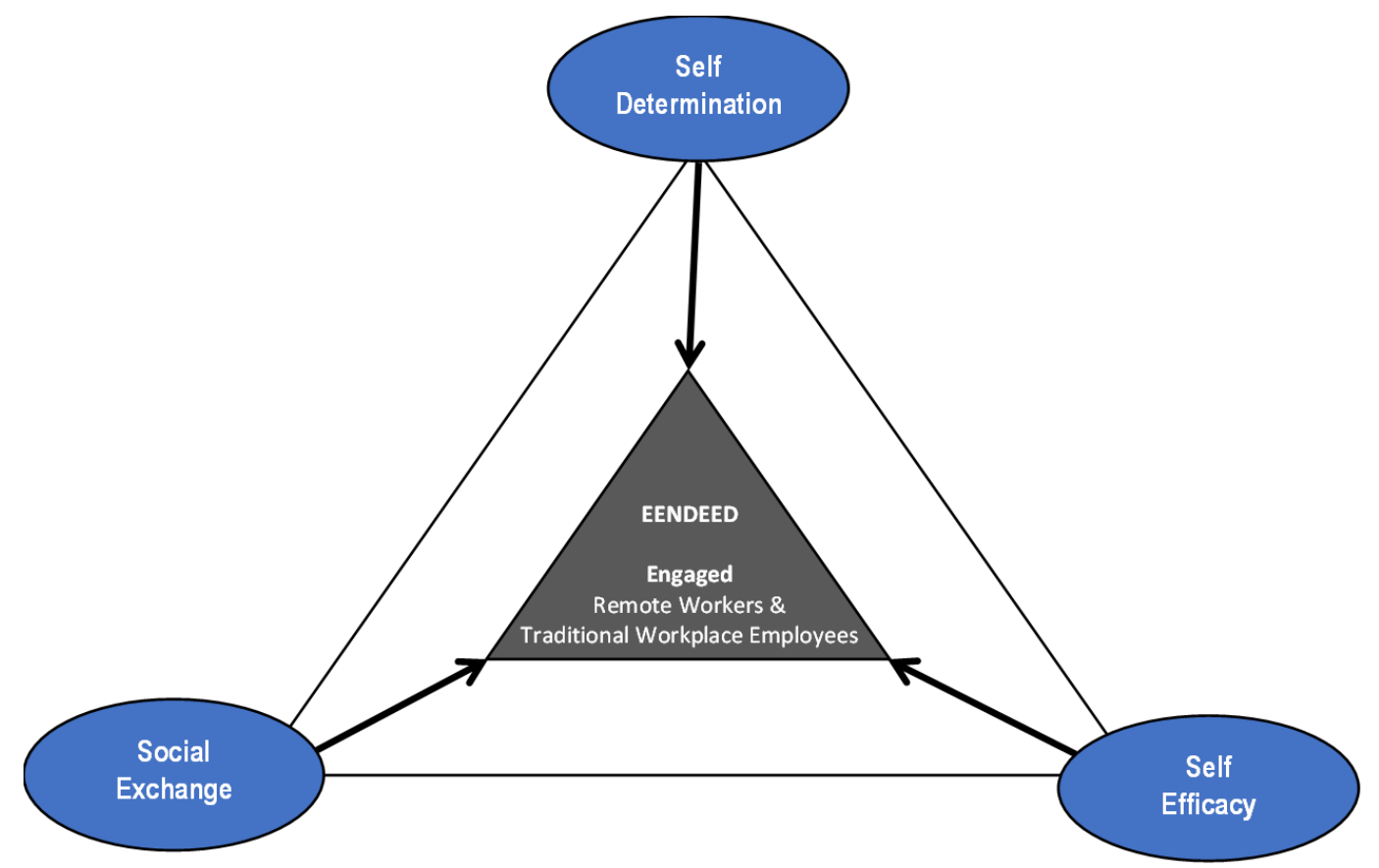

Figure 3. Triadic Model of Employee Engagement as depicted by Lartey and Randall's EENDEED scale

\section{Study 2: Data Collection and Factor Structure of EENDEED Through Exploratory Factor Analysis (EFA) and Confirmatory Factor Analysis (CFA)}

\subsection{Factor Structure of EENDEED Through EFA on 70\% of the Split Dataset}

\subsubsection{Sample \& Data Collection}

Using a random sample from the survey company QuestionPro, data were collected through an online questionnaire from 626 participants. This included both remote and in-office workers in the U.S. As presented in Table $1,45.4 \%$ of participants were male and $54.3 \%$ were female. Two participants (.3\%) selected "other" as their gender. Twenty-two participants did not answer the question (3.5\%).

Table 1. Participants by gender

\begin{tabular}{llcc}
\hline & & Frequency & Percent \\
\hline Valid & Male & 274 & $43.8 \%$ \\
& Female & 328 & $52.4 \%$ \\
& Other & 2 & $.3 \%$ \\
& Total & 604 & $96.5 \%$ \\
Missing gender & & 22 & $3.5 \%$ \\
Total & & 626 & $100 \%$ \\
\hline
\end{tabular}


The data collected were used to discover the underlying factor structure of EENDEED. The initial sample of 626 participants was reduced to 600 cases after removing 26 records with missing values. A 70:30 split was performed on the data, resulting in two datasets. The first had 405 records; the second had 195 records. The larger dataset was used to conduct an exploratory factor analysis (EFA) to discover the factor structure of ENDEED. The smaller dataset would later be used to confirm the identified factor structure.

\subsubsection{Data Analysis}

Initial data purification through the confirmation of the assumptions of EFA identified no multivariate outlier. A descriptive analysis of the measured items showed that none of their z-scores were outside the range of -3.29 to +3.29, as suggested by Tabachnick and Fidell (2013). In addition, all values of skewness and kurtosis were within the range of -1.10 to +1.23 , knowing that acceptable values of skewness are between -3 and +3 . Those for kurtosis are in the range of -10 to +10 when using SEM (Brown, 2006). Georges and Mallery (2010) suggested that these values should be between -2 and +2 to consider the variables normally distributed. As a result, all variables for this study were considered normally distributed and suitable for EFA analysis.

The sample of 405 cases included nine measured items from EENDEED. The ratio of cases to items was over 46 to 1 , above the 5 to 1 ratio used by Bubaš et al. (2003) or 6 to 1 used by Tate et al. (2019). An EFA was, thus, conducted using IBM SPSS version 24.

\subsubsection{Results}

The Kaiser-Meyer-Olkin measure of sampling adequacy was .84, well above the commonly recommended value of .6. Bartlett's test of sphericity was significant $\left(\chi^{2}(36)=1306.66, p<.001\right)$. The correlation matrix in Table 2 showed that most correlations among variables were above .3 , confirming that every item shared a common variance with other items. In addition, all these correlation scores were significant $(p<.001)$. Given all these indicators, a factor analysis using all nine items was deemed suitable.

Table 2. Correlation matrix

\begin{tabular}{lccccccccc}
\hline & \multicolumn{1}{c}{ AUTHEN } & \multicolumn{10}{c}{ MOTIVA EXPRESSI RECOGNI INTERES CAREER AUTONO CONFIDEEMPATH } \\
& TICITY & TION & VENESS & TION & T & PLAN & MY & NCE & Y \\
\hline AUTHENTICITY & 1.000 & .362 & .389 & .360 & .478 & .395 & .373 & .362 & .380 \\
MOTIVATION & .362 & 1.000 & .507 & .453 & .351 & .404 & .296 & .245 & .393 \\
EXPRESSIVENESS & .389 & .507 & 1.000 & .400 & .272 & .423 & .137 & .155 & .281 \\
RECOGNITION & .360 & .453 & .400 & 1.000 & .448 & .547 & .411 & .263 & .365 \\
INTEREST & .478 & .351 & .272 & .448 & 1.000 & .398 & .352 & .372 & .425 \\
CAREERPLAN & .395 & .404 & .423 & .547 & .398 & 1.000 & .329 & .302 & .390 \\
AUTONOMY & .373 & .296 & .137 & .411 & .352 & .329 & 1.000 & .534 & .538 \\
CONFIDENCE & .362 & .245 & .155 & .263 & .372 & .302 & .534 & 1.000 & .689 \\
EMPATHY & .380 & .393 & .281 & .365 & .425 & .390 & .538 & .689 & 1.000 \\
\hline
\end{tabular}

Determinant $=.041$

An EFA was conducted on the sample of 405 cases using maximum likelihood extraction with Promax rotation on nine items. Promax was selected because it is an oblique rotation, which allows factors to be correlated.

Initial eigenvalues indicated that the first two factors explained $45.30 \%$ and $14.27 \%$ of the variance, for a total of $59.58 \%$ of variance explained. Maximum likelihood extraction solutions for two, three, and four factors were evaluated using varimax, direct oblimin, and promax rotations of the factor loading matrix. Only the two-factor solution resulted in an acceptable fitting model.

The final solution yielded two factors. Factor 1 was labelled PERFORMANCE because it presented elements related to job performance, namely AUTHENTICITY, MOTIVATION, EXPRESSIVENESS, RECOGNITION, INTEREST, and CAREERPLAN. Factor 2 loaded three items. It was named SELF-RELIANCE because it included AUTONOMY, CONFIDENCE, and EMPATHY. Table 3 shows a summary of the factors in the resulting pattern matrix. Variables are grouped by loading for the facility of interpretation. Loadings below 3 were suppressed from the table. Factor 1 represents PERFORMANCE; Factor 2 represents SELF-RELIANCE. 
Table 3. Pattern matrix showing the summary of factors

\begin{tabular}{lcc}
\hline & \multicolumn{3}{c}{ Factor } \\
\cline { 2 - 3 } & 1: PERFORMANCE & 2: SELF-RELIANCE \\
\hline AUTHENTICITY & .458 & \\
MOTIVATION & .659 & \\
EXPRESSIVENESS & .717 & \\
RECOGNITION & .705 & \\
INTEREST & .434 & \\
CAREERPLAN & .653 & .579 \\
\hline AUTONOMY & & .958 \\
CONFIDENCE & & .755 \\
EMPATHY & & \\
\hline
\end{tabular}

Extraction Method: Maximum Likelihood.

Rotation Method: Promax with Kaiser Normalization.

Rotation converged in 3 iterations.

After splitting the collected data into two samples of $70 \%$ and 30\%, an EFA was conducted on the larger sample to discover the factor structure of EENDEED. The two factors, labelled PERFORMANCE and SELF-RELIANCE, loaded six and three items, respectively. As a next step, the smaller sample, with $30 \%$ of the cases, was used to confirm the identified factor structure.

\subsection{Confirmation of the Factor Structure of EENDEED through a CFA on 30\% of the Split Dataset}

\subsubsection{Data Sample}

After splitting collected data and performing an EFA on the larger sample, the smaller sample of 195 cases representing approximately $30 \%$ of the initial 600 cases was used for a CFA. This CFA intended to validate that the model with two factors obtained in the previous study would hold true given a different set of data from the same population.

\subsubsection{Model Specification}

The hypothesized model is presented in Figure 4. This model suggests two factors representing EENDEED: PERFORMANCE and SELF-RELIANCE. PERFORMANCE includes AUTHENTICITY, MOTIVATION, EXPRESSIVENESS, RECOGNITION, INTEREST, and CAREERPLAN. The second factor is SELF-RELIANCE, which includes AUTONOMY, CONFIDENCE, and EMPATHY. The two factors are latent or unobserved variables represented in the figure by ovals with capitalized names. The rectangles in the figure are all measured variables. The little circles, e1 to e9, represent error measures.

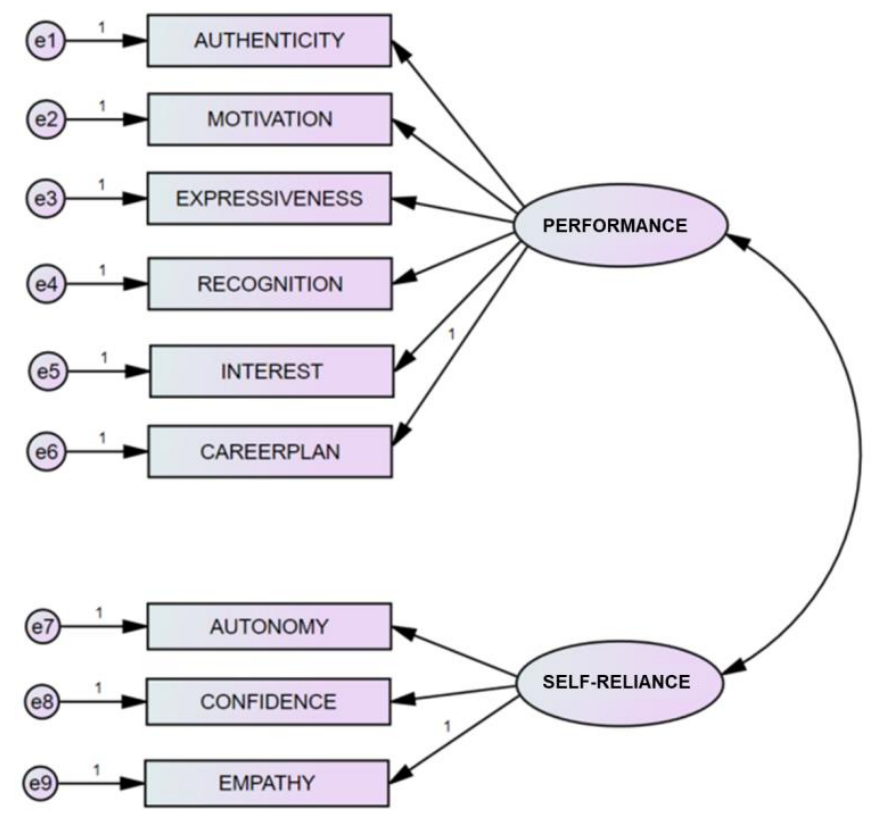

Figure 4. Hypothesized model for EENDEED 
There are two main questions for this analysis. First, does a two-factor model with a simple structure where each variable loads only on one factor fit the data? Second, is there a significant covariance between the different factors in the solution?

\subsubsection{Model Identification}

A preliminary check for identifiability of the model shows that the number of data points is $9 *(9+1) / 2=45$, where 9 is the number of measured variables.

The number of parameters to estimate based on the hypothesized model in Figure 4 was obtained using the following formula:

$$
\begin{aligned}
\# \text { of parameters }= & \quad \text { number of variances (\# of rectangles) } \\
& + \text { number of error terms (e1 ... e9) } \\
& + \text { number of regression coefficients (\# of arrows between constructs) } \\
+ & \text { number of covariances (\# of exogenous variables }- \text { none in this case) }
\end{aligned}
$$

For this study, \# of estimated parameters $=9+9+1+0=19$.

As a result, the model was overidentified with 26 degrees of freedom $(\mathrm{df}=45-19=26)$. The CFA could proceed.

\subsubsection{Assumptions of the CFA}

For this study, there were 195 cases and nine observed variables. The ratio of cases to observed variables was 22:1; the ratio of cases to estimated parameters was 8:1 (with no missing data). Such ratios are adequate for CFA, as suggested by Tabachnick and Fidell (2013).

Normality of the variables was observed through descriptive statistics using IBM SPSS version 24. None of the measured variables had skewness or kurtosis above the -1 to +1 range although the maximum accepted values range from -10 to +10 . In addition, none of the standardized skewness or kurtosis was greater than 3.75 , as suggested by Tabachnick and Fidell (2013).

Linearity of the variables was observed using the graph function of IBM SPSS 24 (Graphs $>$ Legacy $>$ Scatter $>$ Matrix Scatter). Variables were selected into the matrix variable and fit lines were added. The resulting chart was resized to a higher value before each graphic was analyzed. All fit lines had an incline, which confirmed the assumption of linearity. The pairwise variables without a linear relationship would have a flat straight line.

There were no univariate outliers because z-scores were not outside the range of -3.29 to +3.29 . Multivariate outliers were analyzed using the Mahalanobis distance. The probability of the Mahalanobis value was above the chi-square. The results confirmed the absence of multivariate outliers in the dataset.

Multicollinearity and singularity were analyzed using the determinant of the covariance matrix. This determinant was calculated using the dimension reduction option in SPSS. The resulting determinant was computed to .062, which was different from zero. As such, the covariance of the matrix was confirmed to be nonsingular.

Finally, the evaluation of the residuals was performed as part of the model evaluation. This was confirmed with fit indices.

\subsubsection{Model Estimation}

The hypothesized model is represented in Figure 4. Ovals represent the latent variables and rectangles represent the measured variables. Lines connecting variables imply a hypothesized direct effect. Their absence suggests no hypothesized direct effect. A two-factor model was hypothesized with both factors suggested to covarying with one another.

A CFA was performed using Amos version 20 on the sample of 195 cases to investigate if the hypothesized model with two factors fit the data. Maximum likelihood estimation was used. Although the chi-square for the model was significant, $\chi^{2}(26, \mathrm{~N}=195)=54.61, \mathrm{p}<.05$, the normed chi-square value $(\mathrm{CMIN} / \mathrm{DF}=2.10)$ was below 3.0, confirming the good fit of the model to the data. The null hypothesis suggested there was a statistical discrepancy between the model. The actual underlying structure of the data was rejected. In addition, alternative fit indices confirmed this good fit. The goodness of fit index (GFI $=.938)$, comparative fit index $(\mathrm{CFI}=.943)$, Tucker Louis Index (TLI $=.921)$, and Bollen's $(1989)$ incremental fit index $($ IFI $=.944)$ all had values greater than the suggested .9 , indicating a good fit.

In addition, the root means squared error approximation $($ RMSEA $=.075)$ was less than .10 . The PCLOSE $=.068$ 
(PCLOSE > .05) indicates the presence of a close fit model. Hence, it is confirmed there is a good fit between the hypothetical model and the data. With evidence that the hypothesized model fit the data, there was no need for model modification. The results of the CFA in Figure 5 confirmed the two-factor structure of EENDEED.

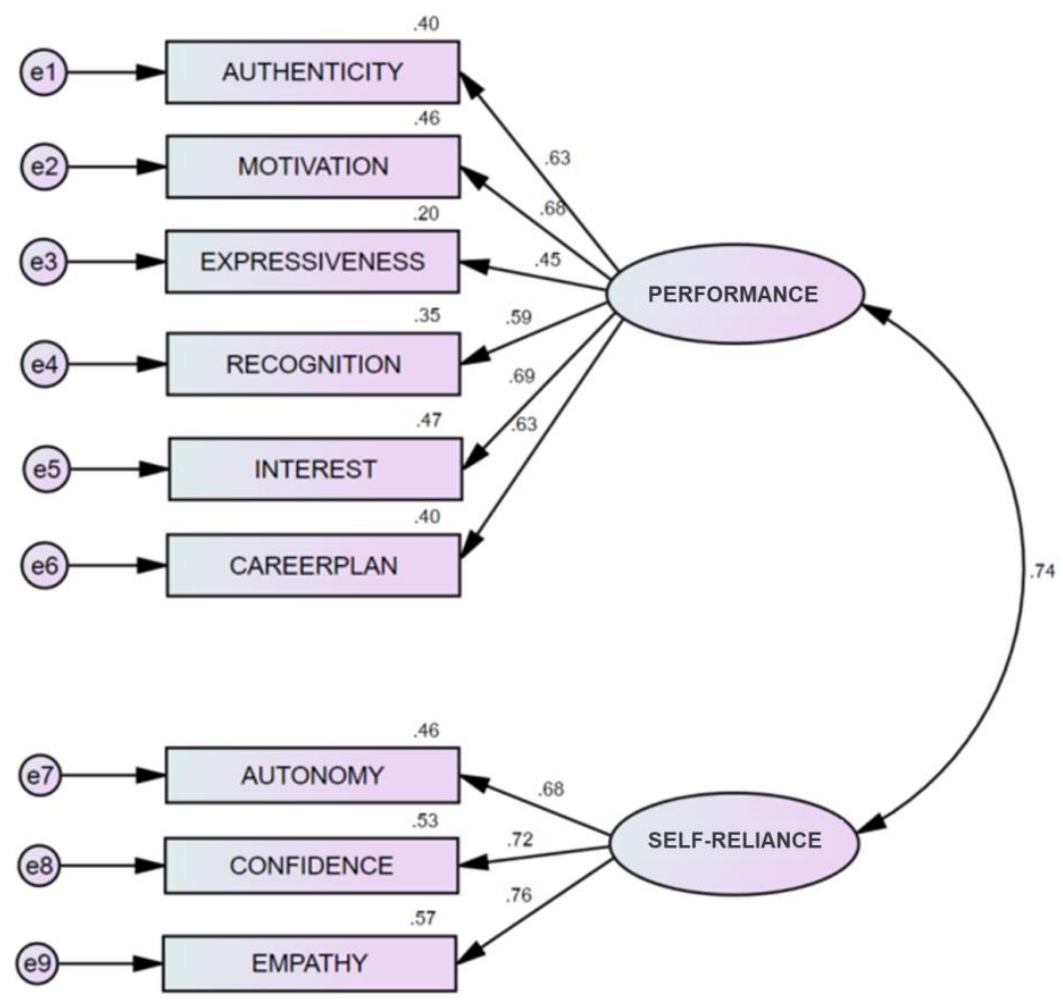

Figure 5. CFA model of the two-factor structure of EENDEED with standardized loading estimates from an analysis of 195 respondents

\section{Study 3: Reliability and Validity Assessment}

Another survey collected data from 162 U.S. employees who were randomly selected by SurveyMonkey. A map of participants within the U.S. is provided in Figure 6. This sample, along with the previous 600 participants that were split into two random samples of 405 and 195 cases, was used in assessing the reliability and validity of EENDEED. First, a CFA was conducted.

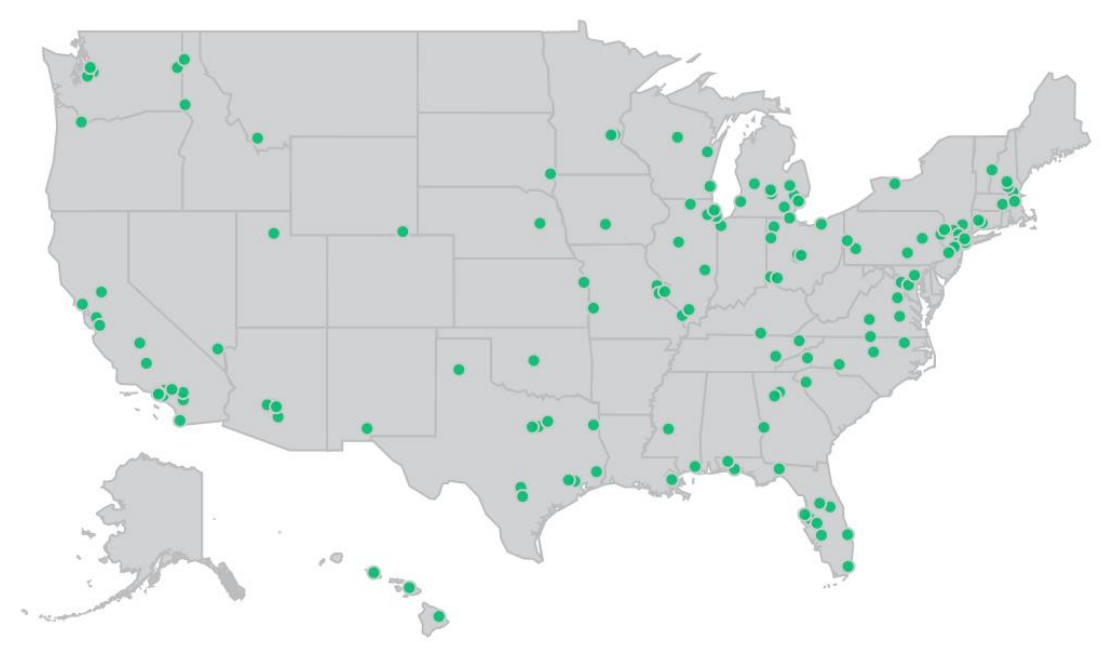

Figure 6. Representation of 162 U.S. participants in second data collection (third sample of this study) 


\subsection{Sample and Data Collection}

Data were collected from 162 employees in the U.S, with $51.2 \%$ male participants and $48.8 \%$ female participants (see Table 5). Responses were obtained within 48 hours after the start of the survey. Overall, 166 people started filling out the survey and four dropped out. The total completion rate was $98 \%$, which is high for such a survey. It also suggests that the EENDEED instrument as presented offers a high level of motivation for participants to complete the questionnaire.

Table 4. Participants by gender.

\begin{tabular}{lcc}
\hline & Frequency & Percent \\
\hline Male & 83 & $51.2 \%$ \\
Female & 79 & $48.8 \%$ \\
Total & 162 & $100 \%$ \\
\hline
\end{tabular}

All participants in the study were 18 years or older. Figure 7 shows the breakdown of participants by age. As shown, $45 \%$ of participants were between 45 and 60 years, $33 \%$ were between 30 and 44, 15\% were between 18 and 29 , and $7 \%$ were over 60 years.

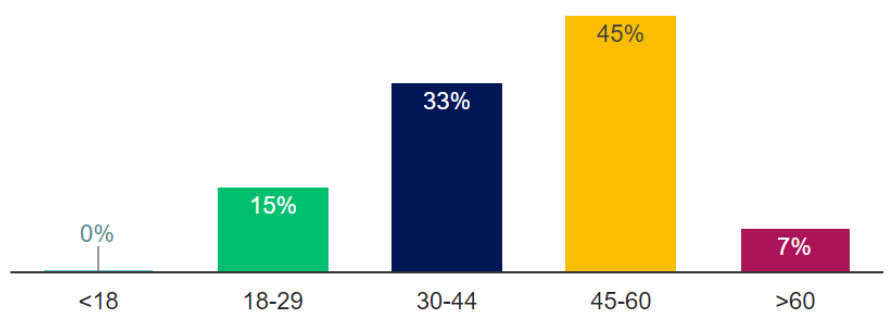

Figure 7. Participants by age

\subsection{Data Analysis}

The analysis of the data to ascertain the assumptions of CFA identified three cases as multivariate outliers. Those cases were not removed from the dataset, as it was determined that they would have almost no influence on the overall statistics. A descriptive analysis of the measured items showed five cases with z-scores slightly outside the range of -3.29 to +3.29 , suggesting possible univariate outliers. A decision was made to keep these cases because, while being less than -3.29 , they were all above -3.4 , suggesting a little impact on the overall effect. All values of skewness and kurtosis were within the range of -1.51 to +2.74 . Values in the range of -3 and +3 are acceptable to consider the variables as normally distributed for SEM. The variables for this study were considered normally distributed and suitable for CFA analysis.

\subsection{Model Identification}

The sample of 159 cases included nine measured items from EENDEED. This resulted in a ratio of cases to items of 18:1. The number of data points was the same as for the previous CFA study, calculated as:

$9 *(9+1) / 2=45$, where 9 is the number of measured variables.

The number of parameters to estimate based on the hypothesized model in Figure 5 was also the same as before, which was estimated to be 19 . The degrees of freedom for the study were valued at 26 . As a result, the model was confirmed to be overidentified and the CFA could proceed.

\subsection{Model Estimation}

A CFA was performed using Amos version 20 on the new sample of 162 cases. This investigated if the hypothesized model with two factors fit the new data. Maximum likelihood estimation was used. Although the chi-square for the model was significant, $\chi^{2}(26, \mathrm{~N}=162)=50.14, \mathrm{p}<.05$, the normed chi-square value $(\mathrm{CMIN} / \mathrm{DF}=1.93)$ was below 3.0, thus confirming the good fit of the model to the data.

In addition, alternative fit indices confirmed the good fit. The goodness of fit index (GFI $=.936$ ), comparative fit index $(\mathrm{CFI}=.942)$, Tucker Louis Index $(\mathrm{TLI}=.919)$, and Bollen's $(1989)$ incremental fit index $(\mathrm{IFI}=.943)$ all 
had values greater than the suggested .9 , indicating a good fit.

Furthermore, the root mean squared error approximation $($ RMSEA $=.076)$ was less than .9 . The PCLOSE $=.088$ (PCLOSE > .05) indicated the presence of a close fit model.

With these indications of a good fit, the null hypothesis suggesting a statistical discrepancy between the model and the actual underlying structure of the data was rejected. Hence, it was confirmed that there was a good fit between the hypothesized model and the data. The results of the CFA in Figure 8 confirmed, yet again, the two-factor structure of EENDEED.

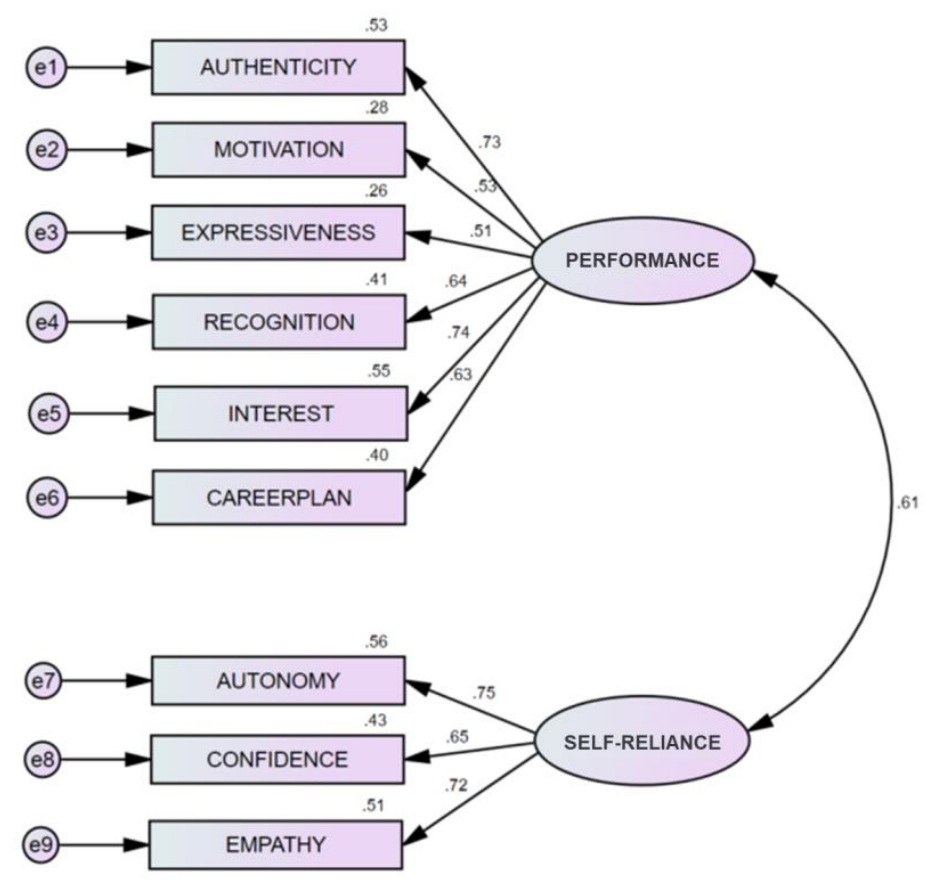

Figure 8.A second confirmation of the two-factor structure of EENDEED with standardized loading estimates from an analysis of 162 respondents

\subsection{Reliability of the EENDEED Scale}

The reliability of EENDEED was assessed using the three samples discussed in the previous studies. The first sample was made of 405 cases, the second of 195 cases, and the third of 162 cases.

\subsubsection{Construct Reliability of the Factors}

A Cronbach alpha reliability test was computed for each of the factors and their measured variables to assess their construct reliability. First, it used the function Analyze>Scale>Reliability Analysis in IBM SPSS. Next, it added only the variables corresponding to one factor at a time. Then, it checked the "scale" and "scale if item deleted" boxes to conduct the test. The result of the tests on the three samples is represented in Table 5, where Sample 1 is the sample with 405 cases, Sample 2 is with 195 cases, and Sample 3 is the newly collected dataset with 162 cases.

Table 5. Reliability of the factors in each sample

\begin{tabular}{lccccc}
\hline Factor & Items & Sample $1 \alpha$ & Sample $2 \alpha$ & Sample $3 \alpha$ & Result \\
\hline PERFORMANCE & 6 & .806 & .775 & .801 & Good \\
SELF-RELIANCE & 3 & .810 & .760 & .744 & Good \\
\hline
\end{tabular}

The general rule for the Cronbach alpha tests suggests that an $\alpha$ of 0.6 to 0.7 indicates an acceptable level of reliability, 0.7 to 0.8 is a good level, and 0.8 or greater is a very good level. All alpha coefficients obtained were either good or very good. The construct reliability of the factors was considered achieved. 


\subsubsection{Reliability of the EENDEED Scale}

The internal consistency of EENDEED was determined using the Cronbach alpha of all items in the measurement instrument. To achieve this, all nine EENDEED measured items were selected for the test. Both samples were evaluated differently. The results in Table 6 indicate that the EENDEED instrument has a very good internal consistency reliability. In other words, there is evidence that all questions in the instrument measure the same construct.

Table 6. Reliability of the EENDEED scale based on the three samples used in this study

\begin{tabular}{lccccc}
\hline & Items & Sample $1 \alpha$ & Sample $2 \alpha$ & Sample $3 \alpha$ & Result \\
\hline EENDEED Instrument & 9 & .845 & .826 & .822 & Very good \\
\hline
\end{tabular}

\subsection{Validity of the EENDEED Scale}

The validity, as explained by Ghauri and Gronhaug (2005), indicates how well the collected data measures what it intends to measure. The assessment of validity can be done using different types of validity. Researchers identified four types of validity, including face, content, construct, and the criterion (Parasuraman et al., 1991; Vogt, 2007).

\subsubsection{Face Validity}

Face validity is a subjective criterion. It indicates the meaningfulness of the scale items, as well as how well they represent the construct being measured. It is the degree to which the items measured tend to be related to the associated construct. In this research, the second study looked at the relationship between the measures of EENDEED and three validated tools to measure engagement as the main construct. The statistically significant positive relationships obtained confirmed these instruments measured a similar construct. The EENDEED instrument is, therefore, considered appropriate in assessing employee engagement in a variety of settings.

\subsubsection{Content Validity}

Content validity measures the degree to which the content of an instrument measures the construct it is intended to measure. This, according to Vogt (2013), is assessed through judgment like expert panels. Taherdoost (2016) contended that it is not always easy to have panel experts work at the same time with all researchers.

The content validity of EENDEED derives from the extensive literature reviewed in building the scale. In a way, all items used in the scale have been validated, thus providing content validity to the scale.

\subsubsection{Construct Validity}

Construct validity reflects how well the idea or behavior theorized by a model is translated or transformed. Construct validity includes convergent and discriminant validity, which were both evaluated for EENDEED.

Convergent validity was assessed using the average variance extracted (AVE) and composite reliability (CR). AVE measures the amount of variance in a construct related to the amount of variance due to measurement error. CR is an estimate of reliability. As explained by Fornell and Larcker (1981), AVE should be greater than .5 and CR should be greater than .6 to demonstrate convergent validity. For this study, a Microsoft Excel table was created to compute the values of AVE and CR for each of the factors using formulas (1) for AVE and (2) for CR as follows:

$$
\begin{gathered}
A V E=\sum \lambda^{2} / N \\
C R=\frac{\sum \lambda^{2}}{\sum \lambda^{2}+\sum\left(1-\lambda^{2}\right)}
\end{gathered}
$$

In these formulas, $\lambda$ is the standardized loading of the item on the factor. $1-\lambda^{2}$ represents the standardized loading error variance of the item. The resulting values of AVE and CR are provided in Table 7. 
Table 7. Values of AVE and CR for the study

\begin{tabular}{lcc}
\hline Factors & PERFORMANCE & SELF-RELIANCE \\
\hline Average Variance Extracted (AVE) & 0.406 & 0.562 \\
Composite Reliability (CR) & 0.801 & 0.749 \\
Convergent Validity & Established & Established \\
\hline
\end{tabular}

All values of CR were above the minimum of the .6 recommendation. The AVE of SELF-RELIANCE is above the recommended .5. PERFORMANCE is below the .5 limit. Fornell and Larcker (1981), as well as Lam (2012), explained that the convergent validity of the construct is adequate if AVE is less than 0.5 and CR is higher than 0.6 . As a result, the convergent validity of EENDEED was established.

The discriminant validity confirms that the constructs measure different things. The discriminant validity of EENDEED was assessed by comparing the squared correlations and AVE scores for each pairwise construct as suggested by Fornell and Larcker (1981). The results are shown in Table 8, which contains the discriminant validity of the pairwise constructs. There was only one such pairwise item to compare because EENDEED has only two factors forming a pair.

Table 8. Pairwise discriminant validity of EENDEED factors

\begin{tabular}{ccccccc}
\hline Factor 1 & Factor 2 & $\begin{array}{c}\text { Standard } \\
\text { Correla- } \\
\text { tion }\end{array}$ & $\begin{array}{c}\text { Square } \\
\text { Standar- } \\
\text { dized } \\
\text { Correla- } \\
\text { tion }\end{array}$ & $\begin{array}{c}\text { AVE } \\
\text { Factor 1 }\end{array}$ & $\begin{array}{c}\text { AVE } \\
\text { Factor } \\
2\end{array}$ & $\begin{array}{c}\text { Discriminant } \\
\text { Validity } \\
\text { (AVE > Sq } \\
\text { Correlation) }\end{array}$ \\
\hline PERFORMANCE & SELF-RELIANCE & 0.614 & 0.377 & 0.406 & 0.562 & Established \\
\hline
\end{tabular}

As shown in Table 8, EENDEED exhibited discriminant validity of its pairwise factors. All values of pairwise AVE were above their squared standardized correlations. As a result, the discriminant validity of EENDEED was deemed met.

\subsubsection{Criterion Validity}

Criterion validity measures how well the instrument predicts the outcome. In the case of EENDEED, criterion validity would assess how well an employee's level of engagement can be predicted from their answers to the questions in the instrument.

Criterion validity of EENDEED was assessed through the regression of the instrument to a self-reported engagement score filled by participants. The item was measured on a Likert scale from 1 to 5 ( 1 being "strongly disagree," the employee is not engaged at all and 5 being "strongly agree," the employee feels fully engaged in their job). The item read: "I am very engaged in my current job." The factors of EENDEED were calculated as the average of their items. The resulting factor scores were regressed on this self-reported engagement item using a multiple regression model. The goal of this model was to ascertain the ability to predict self-reported employee engagement. This method is consistent with that used by Parasuraman et al. (1988) in establishing the criterion validity of SERVQUAL, an instrument for measuring customer perception of service quality (Lartey, 2015; Lartey et al., 2015). A Cronbach analysis on the 10-item questionnaire and 162 cases showed an alpha score of .852. Such a high alpha value confirms the internal consistency of the questionnaire, suggesting that the additional question measured the same thing as the EENDEED instrument.

After validating the assumptions of multiple regression, a standard multiple regression model was created to assess the ability to predict the self-reported employee engagement (SELF-ENGAGEMENT) using the factors of EENDEED, namely PERFORMANCE and SELF-RELIANCE, calculated as the average score of their items. This model confirmed the existence of the significant regression equation, $F(2,161)=115.77, p<.001$. The summary of the multiple regression model is presented in Table 9. The $R$-square confirms that the model explains $59.3 \%$ of the variability in a self-reported engagement score. In addition, Table 10 shows that both IVs (PERFORMANCE and SELF-RELIANCE) are significant in predicting self-reported employee engagement ( $p$ $<.001)$. Based on these results, EENDEED's criterion validity, which measures how well the instrument predicts 
the outcome, was confirmed.

Table 9. Model summary with SELF-ENGAGEMENT as DV

\begin{tabular}{lcccc}
\hline Model & $\mathrm{R}$ & R Square & Adjusted R Square & Std. Error of the Estimate \\
\hline $1^{\mathrm{a}}$ & $.770^{\mathrm{a}}$ & .593 & .588 & .67643 \\
\hline
\end{tabular}

a. Predictors: (Constant), SELF-RELIANCE, PERFORMANCE

Table 10. Model coefficients

\begin{tabular}{|c|c|c|c|c|c|c|c|}
\hline \multirow[b]{2}{*}{ Model } & \multicolumn{2}{|c|}{$\begin{array}{l}\text { Unstandardized } \\
\text { Coefficients }\end{array}$} & \multirow{2}{*}{$\begin{array}{c}\begin{array}{c}\text { Standardized } \\
\text { Coefficients }\end{array} \\
\text { Beta }\end{array}$} & \multirow[b]{2}{*}{$\mathrm{t}$} & \multirow[b]{2}{*}{ Sig. } & \multicolumn{2}{|c|}{ Collinearity Statistics } \\
\hline & $\mathrm{B}$ & Std. Error & & & & Tolerance & VIF \\
\hline $1^{\mathrm{a}}$ (Constant) & -.648 & .311 & & -2.081 & .039 & & \\
\hline PERFORMANCE_AVG & .473 & .071 & .380 & 6.670 & .000 & .789 & 1.267 \\
\hline SELF_RELIANCE_AVG & .732 & .081 & .518 & 9.085 & .000 & .789 & 1.267 \\
\hline
\end{tabular}

a. DV: SELF-ENGAGEMENT

\section{Discussions and Conclusion}

\subsection{Theoretical Contribution: Enhanced Engagement Scale}

Over the years, HRD scholars and practitioners have made multiple attempts to develop scales to measure the engagement of traditional workplace employees (Gupta \& Sharma, 2018; Shrotryia \& Dhanda, 2019). However, the literature does not show similar efforts applied to the burgeoning workforce of remote workers. This study contributed to theory by providing an instrument that accounts for remote workers when measuring employee engagement. Hence, it filled the existing gap identified in the literature related to the measurement of remote employee engagement.

For the purposes of this research, the authors offered a definition of worker engagement based on the assumption advanced by Ababneh et al. (2019): engagement can be changed. Change is done so by modifying the conditions under which one's work is offered. This definition aligns with Lartey (2021), suggesting that engagement is:
a two-way relationship between an organization and a worker, in which the organization provides the worker with the environment and conditions to be successful through good leadership and management, and the worker provides the organization with a positive and self-motivated performance leading to the achievement of the organizational mission, vision, purpose, and goals. (p. 137)

This definition aligns with the triadic representation of engagement discussed in this study. The EENDEED instrument anchors and informs the theoretical foundation of engagement on three theories: (1) self-determination; (2) self-efficacy; and (3) social exchange.

The self-determination theory includes competence, autonomy, and relatedness constructs. The social-exchange theory and its concomitant attributes can be summarized as a person who favorably considers others with the expectation of something in return. Both theories boast the strength and centrality of the individual in controlling their environment (Homans, 1958). This is further emphasized and reinforced in the SEFT of Bandura (1977).

This study offered an instrument that can be used in academia for research on worker engagement. Such research could seek the relationship between engagement and other constructs, look at the mediating or moderating effect of factors on engagement, or study engagement as a moderator or a mediator in other settings.

\subsection{Practical Contribution: Enhanced Engagement Scale}

Organizations like Facebook, Twitter, and Deutsche Bank continue to express interest in maintaining and/or increasing the opportunity for employees to work remotely post-Covid-19 (Duffy, 2021). The understanding of remote workers' engagement and aspects of worker isolation seems daunting for leaders and human capital professionals across the globe as they strive to build an organizational culture with many people working from home. Organizational leaders residing in the executive suite or management can use this instrument to assist in 
the development of remote worker engagement strategies to improve workplace isolation and enhance remote worker engagement.

The confluence of Covid-19 and the new mode of work generated by the availability of advanced ICTs have created a unique opportunity for organizations to assess both their traditional workplace and remote worker engagement, as well as identify roadblocks to their success. This instrument is offered to catalyze and guide companies in examining how best to organize work designs and engagement strategies for both remote workers and traditional workplace employees. In the end, organizations may benefit from such an examination in terms of employee productivity, achievement of organizational goals, customer satisfaction, and talent retention.

Staples et al. (1999) suggested that remote employees' self-efficacy assessments play a critical role in influencing the effectiveness of remote workers and their productivity and job satisfaction. Given this position, organizations and human capital professionals should arguably consider the employees' self-efficacy-driven desires in designing remote work arrangements and designs. This idea is corroborated by Gratton's (2021) Harvard Business Review article "How to Do Hybrid Right," where she addresses the design of flexible work arrangements.

\subsection{Limitations and Future Research}

The current instrument was created with data gathered from workers in the U.S. As such, the findings from this study should not be generalized to other countries. Hence, further research is needed to confirm these findings and extend the generalizability of EENDEED.

This is the inception of ENDEED. Therefore, additional research is required to assess and confirm the validity of the instrument. Future research can also focus on establishing the content validity of the instrument through a panel of experts. Content validity was established here through an extensive literature review. Yet a panel of experts would confirm and enhance such validity.

A study based on EENDEED needs to be conducted in a controlled area where the researcher has access to participants and their supervisors. In such a case, the researcher can follow up with participants for clarification on their provided answers. Findings in this setting would increase the validity of the instrument. Indeed, the data used in the current study was collected online. There was no possibility of contacting participants or obtaining their reporting structure in which supervisors could confirm the engagement level of participants.

\section{Acknowledgments}

This study was fully funded by the authors without any external support or grant. We wish to acknowledge the following individuals for their review and comments during the development of this instrument: Dr. Tiffany Dotson, Vice President, Global Talent, Leadership, and Learning at Liberty Mutual Ins, Boston, MA.; Ms. Deborah Hyman, Vice President, Global Technology Communications at MetLife, New York, NY.; Dr. Susan Saurage-Altenloh, Chief Insights Officer and Founder of Saurage Research, Inc., Houston. TX; and Dr. Tywanda Tate, Owner, Prosperity Business Solutions Group, LLC, Mobile, AL.

\section{References}

Ababneh, O., Lefevre, M., \& Bentley, T. (2019). Employee engagement: development of a new measure, International Journal of Human Resources Development and Management, 19(2), 105-134. https://doi.org/10.1504/IJHRDM.2019.098623

Allen, T. D., Shockley, K. M., \& Biga, A. (2010). Work and family in a global context. In K. Lundby (Ed.), Going global: Practical applications and recommendations for $H R$ and OD professionals in the global workplace (pp. 377-401). San Francisco, CA: Jossey-Bass.

Anitha, J. (2014). Determinants of employee engagement and their impact on employee performance. International Journal of Productivity and Performance Management, 63(3), 308-323. https://doi.org/10.1108/IJPPM-01-2013-0008

Aryee, S., Budhwar, P. S., \& Chen, Z. X. (2002, May). Trust a mediator of the relationship between organizational justice and work outcomes: Test of a social exchange model. Journal of Organizational Behavior, 23, 267-285. https://doi.org/10.1002/job.138

Bakker, A. B., \& Bal, P. M. (2010). Weekly work engagement and performance: A study among starting teachers. Journal of Occupational and Organizational Psychology, 83, 189-206. https://doi.org/10.1348/096317909X402596

Bakker, A. B., \& Schaufeli, W. B. (2008). Positive organizational behavior: Engaged employees in flourishing 
organizations. Journal of Organizational Behavior, 29, 147-154. https://doi.org/10.1002/job.515

Bakker, A. B., Albrecht, S. L., \& Leiter, M. P. (2011). Key questions regarding work engagement. European Journal of Work and Organizational Psychology, 20, 4-28. https://doi.org/10.1080/1359432X.2010.485352

Bandura, A. (1977). Self-efficacy: Toward a unifying theory of behavioral change. Psychological Review, 84(2), 191-215. https://doi.org/10.1037/0033-295X.84.2.191

Bandura, A. (1986). Social foundations of thought and action. A social cognitive theory. Englewood Cliffs, NJ: Prentice Hall.

Bandura, A. (1994). Self-efficacy. In V. S. Ramachaudran (Ed.), Encyclopedia of human behavior (vol. 4, pp. 71-81). New York, NY: Academic Press.

Bandura, A. (2006). Guide for constructing self-efficacy scales. In F. Pajares \& T. Urdan (Eds.), Self-efficacy beliefs of adolescents (vol. 5, pp. 307-337). Greenwich, CT: Information Age Publishing.

Barsness, Z. I., Diekmann, K. A., \& Seidel, M. L. (2005). Motivation and opportunity: The role of remote work, demographic, dissimilarity, and social network centrality in impression management. Academy of Management Journal, 48(3), 401-419. https://doi.org/10.5465/amj.2005.17407906

Blau, P. M. (1964). Exchange and power in social life. New York, NY: John Wiley.

Bollen, K. (1989). A new incremental fit index for general structural equation models. Sociological Methods and Research, 17(3), 303-316. https://doi.org/10.1177/0049124189017003004

Bowden, J. L. (2009). The process of customer engagement: A conceptual framework. Journal of Marketing Theory and Practice, 17(1), 63-74. https://doi.org/10.2753/MTP1069-6679170105

Brenan, M. (2020, April). U.S. workers discovering affinity for remote work. Gallup Inc. Retrieved from https://news.gallup.com/poll/306695/workers-discovering-affinity-remote-work.aspx

Brown, T. A. (2006). Confirmatory factor analysis for applied research. New York, NY: The Guilford Press.

Bubas, G. (2006). Competence in computer-mediated communication: An evaluation and potential use of a self-assessment measure. International Communication Association Conference (pp. 1-26).

Bubaš, G., Radoš ević, D., \& Hutinski, Ž. (2003) Assessment of Computer Mediated Communication Competence: Theory and Application in an Online Environment. Journal of Information and Organizational Sciences, 27, 55-67.

Budworth, M., \& Latham, G. P. (2009). New directions in industrial-organizational psychology. Canadian Journal of Behavioural Science, 41(4), 193-194. https://doi.org/10.1037/a0015585

Carmona-Halty, M. A., Schaufeli, W. B., \& Salanova, M. (2019). The Utrecht Work Engagement Scale for Students (UWES-9S): Factorial validity, reliability, and measurement invariance in a Chilean sample of undergraduate university students. Frontiers in Psychology, 10. https://doi.org/10.3389/fpsyg.2019.01017

Chandni, S., \& Rahman, Z. (2020). Customer engagement and employee engagement: Systematic review and future directions. The Service Industries Journal, 40(13-14), 932-959. https://doi.org/10.1080/02642069.2020.1733534

Deci, E. L., \& Ryan, R. M. (1985). Intrinsic motivation and self-determination in human behavior. New York, NY: Plenum. https://doi.org/10.1007/978-1-4899-2271-7

Deckop, J. R., Cirka, C. C., \& Andersson, L. (2003). Doing unto others: The reciprocity of helping behavior in organizations. Journal of Business Ethics 47(2), 101-113. https://doi.org/10.1023/A:1026060419167

Duffy, K. (2021). Deutsche Bank says it will let staff work from home 3 days a week when offices open. Business Insider. Retrieved May 2, 2021, from https://www.businessinsider.com/deutsche-bank-staff-flexible-work-from-home-three-days-week-2021-4

Emerson, R. M. (1976, August). Social exchange theory. Annual Review of Sociology, 2, 335-362. https://doi.org/10.1146/annurev.so.02.080176.002003

Fornell, C., \& Larcker, D. F. (1981). Evaluating structural equation models with unobservable variables and measurement error. Journal of Marketing Research, 18(1), 39-50. https://doi.org/10.1177/002224378101800104

Garrin, J. M. (2014). Self-efficacy, self-determination, and self-regulation: The role of the fitness professional in social change agency. Journal of Social Change, 6(1), 41-54. 
George, D., \& Mallery, M. (2010). SPSS for Windows step by step: A simple guide and reference, 17.0 update (10a ed.) Boston, MA: Pearson.

Ghauri, P., \& Gronhaug, K. (2005). Research methods in business studies. Harlow: FT/Prentice Hall.

Gouldner, A. W. (1960, April). The norm of reciprocity: A preliminary statement. American Sociological Review, 25(2), 161-178. https://doi.org/10.2307/2092623

Grant, C. A., Wallace, L. M., \& Spurgeon, P. C. (2013). An exploration of the psychological factors affecting remote e-worker's job effectiveness, well-being and work-life balance. Employee Relations, 35, 527-546. https://doi.org/10.1108/ER-08-2012-0059

Gratton, L. (2021). How to do hybrid right. Harvard Business Review, 9(3), 66-74.

Gull, I. A., Khan, A., \& Sheikh, A. M. (2020). Employee engagement-performance relationship through innovative work behaviour and intention to stay. International Journal of Information, Business and Management, 12(4), 79-87.

Gupta, N., \& Sharma, V. (2018). The comparative analysis of employee engagement measures: A theoretical perspective. International Journal of Management Practice, 11(1), 4. https://doi.org/10.1504/IJMP.2018.088382

Hakanen, J. J., Bakker, A. B., \& Schaufeli, W. B. (2006). Burnout and work engagement among teachers. Journal of School Psychology, 43, 495-513. https://doi.org/10.1016/j.jsp.2005.11.001

Hart, J. (2020). U.S. employee engagement hits new high after historic drop. Workplace, Gallup, Inc.

Harter, J. K., Schmidt, F. L., \& Hayes, T. L. (2002). Business-unit-level relationship between employee satisfaction, employee engagement, and business outcomes: A meta-analysis. Journal of Applied Psychology, 87(2), 268-279. https://doi.org/10.1037/0021-9010.87.2.268

Hartman, F., \& Guss, C. (1996). Virtual teams-Constrained by technology or culture. Proceedings of IEMC 96. Managing virtual enterprises: A convergence of communications, computing, and energy technologies (pp. 645-650). Vancouver, BC, Canada: IEEE.

Hewlett-Packard. (2017). Timeline of our history. Retrieved from http://www8.hp.com/us/en/hp-information/about-hp/history/hptimeline/timeline.html?jumpid=reg_r1002_u sen_c-001_title_r0001

Homans, G. C. (1958). Social behavior as exchange. American Journal of Sociology, 63(6), 597-606. https://doi.org/10.1086/222355

Isaac, R. G., Zerbe, W. J., \& Pitt, D. C. (2001). Leadership and motivation: The effective application of expectancy theory. Journal of Managerial Issues, 13(2), 212-226. Retrieved from http://search.proquest.com/docview/194165049?accountid=39364

Johnston, A. C., Wech, B., \& Jack, E. (2013). Engaging remote employees: The moderating role of "remote" status in determining employee information security policy awareness. Journal of Organizational and End User Computing, 25(1), 1. https://doi.org/10.4018/joeuc.2013010101

Judge, T. A., Erez, A., \& Bono, J. E. (1998). The power of being positive: The relation between positive self-concept and job performance. Human Performance, 11, 167-187. https://doi.org/10.1207/s15327043hup1102\&3_4

Kazimoto, P. (2016). Employee engagement and organizational performance of retails enterprises. American Journal of Industrial and Business Management, 6, 516-525. https://doi.org/10.4236/ajibm.2016.64047

Kim, S., \& Kuo, M. (2015). Examining the relationships among coaching, trustworthiness, and role behaviors: A social exchange perspective. The Journal of Applied Behavioral Science, 5, 152-176. https://doi.org/10.1177/0021886315574884

Lam, L. W. (2012). Impact of competitiveness on salespeople's commitment and performance. Journal of Business Research, 65(9), 1328-1334. https://doi.org/10.1016/j.jbusres.2011.10.026

Lartey (2015). Increasing promoters in the residential broadband service industry: Relationship between customer satisfaction and loyalty using ordinal logistic regression. [Doctoral dissertation, Capella University]. ProQuest Dissertations Publishing.

Lartey, F. M. (2021). Impact of career planning, employee autonomy, and manager recognition on employee engagement. Journal of Human Resource and Sustainability Studies, 9(2), 135-157. 
https://doi.org/10.4236/jhrss.2021.92010

Lartey, F. M., \& Randall, P. M. (2021a). Indicators of computer-mediated communication affecting remote employee engagement. Journal of Human Resource and Sustainability Studies, 9(2), 82-92. https://doi.org/10.4236/jhrss.2021.91006

Lartey, F. M., \& Randall, P. M. (2021b). From the balanced measure of psychological needs (BMPN) to employee engagement: Indicators that matter. International Business Research, 14(6), 99-107. https://doi.org/10.5539/ibr.v14n6p99

Lartey, F. M., Hargiss, K., \& Howard, C. (2015). Antecedents of customer satisfaction on affecting loyalty: An implementation of SERVQUAL and NPS. International Journal of Strategic Information Technology and Applications, 6, 27-42. https://doi.org/10.4018/IJSITA.2015010103

Legault, L. (2017). Self-determination theory. In V. Zeigler-Hill \& T. Shackelford (Eds.), Encyclopedia of personality and individual differences. Springer. https://doi.org/10.1007/978-3-319-28099-8_1162-1

Lombardo, C. P. (2011). Remote management styles: Analyzing the effects of relational psychological contracts and leadership style on teleworkers [doctoral dissertation]. Retrieved from ProQuest Dissertations and Theses database. (Order No. 3509281)

Macey, W., \& Schneider, B. (2008). The meaning of employee engagement. Industrial and Organizational Psychology, 1, 3-30. https://doi.org/10.1111/j.1754-9434.2007.0002.x

Madsen, S. R. (2001). The benefits, challenges, and implication of teleworking: A literature review. Journal of Culture and Religion, 1, 148-158.

Maitland, A., \& Thomson, P. (2014). Future work (expanded and updated): Changing organizational culture for the new world of work. London, UK: Springer. https://doi.org/10.1057/9781137367167

Malone, G. P., Pillow D. R., \& Osman A. (2012). The general belongingness scale (GBS): Assessing achieved belongingness. Personality and Individual Differences 52, 311-316. https://doi.org/10.1016/j.paid.2011.10.027

Men, L. R., O'Neil, J., \& Ewing, L. (2020). Examining the effects of internal social media usage on employee engagement. Public Relations Review, 46(2). https://doi.org/10.1016/j.pubrev.2020.101880

Meyer, J. P. (2013). The science-practice gap and employee engagement: It's a matter of principle. Canadian Psychology, 54, 235-245. https://doi.org/10.1037/a0034521

Michel, J. W., \& Tews, M. J. (2016). Does leader-member exchange accentuate the relationship between leader behaviors and organizational citizenship behaviors? Journal of Leadership \& Organizational Studies, 23, 13-26. https://doi.org/10.1177/1548051815606429

Nilles, J. (1975). Telecommunications and organizational decentralization. IEEE Transactions on Communications, 23, 1142-1147. https://doi.org/10.1109/TCOM.1975.1092687

Parasuraman, A., Berry, L. L., \& Zeithaml, V. A. (1991). Refinement and reassessment of the SERVQUAL scale. Journal of Retailing, 67(4), 420-450.

Parasuraman, A., Zeithaml, V. A., \& Berry, L. L. (1988). SERVQUAL: A multiple-item scale for measuring consumer perception of service quality. Journal of Retailing, 64(1), 12-40.

Randall, P. M., Lartey, F. M., \& Tate, T. D. (2020). Enterprise social media (ESM) use and employee belongingness in US corporations. Journal of Human Resource Management, 8(3), 115-124. https://doi.org/10.11648/j.jhrm.201200803.12

Rich, B. L., LePine, J. A., \& Crawford, E. R. (2017). Job engagement: Antecedents and effects on job performance. Academy of Management Journal, 53(3), 617-635. https://doi.org/10.5465/amj.2010.51468988

Romppel, M., Herrmann-Lingen, C., Wachter, R., Edelmann, F., Düngen, H., Pieske, B., \& Gesine Grande, G. (2013). A short form of the General Self-Efficacy Scale (GSE-6). Psycho-Social-Medicine, 10. https://doi.org/10.1037/t69316-000

Rosen, C. C., Harris, K. J., \& Kacmar, K. M. (2011). LMX, context perceptions, and performance: An uncertainty management perspective. Journal of Management, 37, 819-838. https://doi.org/10.1177/0149206310365727

Ryan, R. M., \& Deci, E. L. (2000). Self-determination theory and the facilitation of intrinsic motivation, social 
development, and well-being. American Psychologist, 55(1), 68-78. https://doi.org/10.1037/0003-066X.55.1.68

Saks, A. M. (2006). Antecedents and consequences of employee engagement. Journal of Managerial Psychology, 21(7), 600-619. https://doi.org/10.1108/02683940610690169

Salanova, M., Agut, S., \& Peiró, J. M. (2005). Linking organizational resources and work engagement to employee performance and customer loyalty: The mediation of service climate. Journal of Applied Psychology, 90(6), 1217-1227. https://doi.org/10.1037/0021-9010.90.6.1217

Schaufeli, W. B. (2014). What is engagement? In C. Truss, R. Delbridge, K. Alfes, A. Shantz, \& E. Soanne (Eds.), Employee engagement in theory and practice (pp. 15-35). Abingdon, UK: Routledge.

Schaufeli, W. B., \& Bakker, A. B. (2004). Job demands, job resources, and their relationship with burnout and engagement: A multi-sample study. Journal of Organizational Behavior, 25, 293-315. https://doi.org/10.1002/job.248

Scherbaum, C., Cohen-Charash, Y., Michael, C., \& Kern, J. (2006). Measuring general self-efficacy: A comparison of three measures using item response theory. Educational and Psychological Measurement, 66(6), 1047-1063. https://doi.org/10.1177/0013164406288171

Shrotryia, V. K., \& Dhanda, U. (2019). Measuring employee engagement: Perspectives from literature. The IUP Journal of Organizational Behavior, 18(3), 26-47.

Shuck, B., Twyford, D., Reio, T. G., \& Shuck, A. (2014). Human resource development practices and employee engagement: Examining the connection with employee turnover intentions. Human Resource Development Quarterly, 25, 239-270. https://doi.org/10.1002/hrdq.21190

Slack, R. E., Corlett, S., \& Morris, R. (2015). Exploring employee engagement with (corporate) social responsibility: A social exchange perspective on organisational participation. Journal of Business Ethics, 127, 537. https://doi.org/10.1007/s10551-014-2057-3

Soper, D. (2021). A-priori sample size for structural equation models calculator. Retrieved from https://www.danielsoper.com/statcalc/calculator.aspx $? \mathrm{id}=89$

Spitzberg, B. H. (2006). Preliminary development of a model and measure of computer-mediated communication (CMC) competence. Journal of Computer-Mediated Communication, 11, 629-666. https://doi.org/10.1111/j.1083-6101.2006.00030.x

Staples, D. S., Hulland, J. S., \& Higgins, C. A. (1999). A self-efficacy theory explanation for the management of remote workers in virtual organizations. Organizational Science, 10(6), 693-815.

https://doi.org/10.1287/orsc.10.6.758

Sweet, S. N., Fortier, M. S., Strachan, S. M., Blanchard, C. M., \& Boulay, P. (2014). Testing a longitudinal integrated self-efficacy and self-determination theory model for physical activity post-cardiac rehabilitation. Health Psychology Research, 2, 30-37. https://doi.org/10.4081/hpr.2014.1008

Tabachnick, B. G., \& Fidell, L. S. (2013). Using multivariate statistics (6th ed.). Upper Saddle River, NJ: Pearson.

Taber, K. T. (2018). The use of Cronbach's alpha when developing and reporting research instruments in science education. Research in Science Education, 48(6), 1273-1296. https://doi.org/10.1007/s11165-016-9602-2

Taherdoost (2016). Validity and reliability of the research instrument; How to test the validation of a questionnaire/survey in a research. SSRN Electronic Journal 5(3), 28-36. https://doi.org/10.2139/ssrn.3205040

Tate, T. D. (2015). Performance management and employee engagement in small businesses: A correlation analysis [Doctoral dissertation, Capella University]. ProQuest Dissertations Publishing.

Tate, T. D., Lartey, F. M., \& Randall, P. M. (2019). Relationship between computer-mediated communication and employee engagement among telecommuting knowledge workers. Journal of Human Resource and Sustainability Studies, 7, 328-347. https://doi.org/10.4236/jhrss.2019.72021

Ter Hoeven, C. L., \& Van Zoonen, W. (2015). Flexible work designs and employee well-being: Examining the effects of resources and demands. New Technology, Work and Employment, 30, 237-255.

https://doi.org/10.1111/ntwe.12052

Thibaut, J. W., \& Kelley, H. H. (1959). The social psychology of groups. John Wiley. 
Vogt, P. (2007). Quantitative research methods for professionals. MA: Pearson Education.

Vogt, P. (2007). Quantitative research methods for professionals. Massachusetts: Pearson Education.

White, D. W., Harrison, J. C, \& Turner, S. (2010). Does customer engagement with Internet-based services influence adoption of other new products? Canadian Journal of Administrative Sciences, 27, 68-75. https://doi.org/10.1002/cjas.134

WorldatWork. (2009). Telework trendlines 2009. Retrieved from https://www.worldatwork.org/media/CDN/resources/surveys/survey-brief-telework-trendlines-2009.pdf

Yakovleva, M., Reilly, R. R., \& Werko, R. (2010). Why do we trust? Moving beyond individual to dyadic perceptions. Journal of Applied Psychology, 95(1), 79-91. https://doi.org/10.1037/a0017102

\section{Appendix A}

\section{The EENDEED Instrument}

EENDEED is a nine-item instrument used for measuring the engagement of remote employees and traditional office workers. The nine items are statements answered using a five-point Likert scale ranging from (1) Strongly disagree to (5) Strongly agree. The first six items of the scale represent the construct of PERFORMANCE, and the last three represent the construct of SELF-RELIANCE. The instrument is presented as follows:

1. At work, my choices express my "true self"

2. I look forward to sitting down at my computer to write to others or do my daily work

3. I use a lot of expressive symbols in my communication messages, such as :-) or $;$ ) for "smile", lol for "laugh", etc.

4. I am satisfied with the recognition I receive from my supervisor

5. At my job, I am doing what really interests me

6. I had a career-planning discussion with my manager

7. I have control over the quality of my work

8. I successfully complete difficult tasks and projects

9. I show concern for and interest in the person I am conversing with, in my communication messages

All items are scored using a 5-point Likert scale ranging from 1 to 5 as follows:

1. Strongly disagree

2. Disagree

3. Neither agree nor disagree

4. Agree

5. Strongly agree

\section{Copyrights}

Copyright for this article is retained by the author(s), with first publication rights granted to the journal.

This is an open-access article distributed under the terms and conditions of the Creative Commons Attribution license (http://creativecommons.org/licenses/by/4.0/). 